\title{
TEMPORAL AND SPATIAL VARIATION CHARACTERISTICS OF PM2.5 CONCENTRATION IN "2+26" CITIES
}

\author{
Lisi Liang ${ }^{1}$, Juanli Jing ${ }^{1,2, *}$, Anna Wang ${ }^{1}$, Fulin Luo ${ }^{1}$ \\ ${ }^{1}$ College of Geomatics and Geo-information, Guilin University of Technology \\ ${ }^{2}$ Guangxi Key Laboratory of Spatial Information and Geomatics, Guilin 541004, China
}

Commission VI, WG VI/4

KEY WORDS: Air Pollution, PM2.5 Concentration, Beijing-Tianjin-Hebei Region,"2+26" Cities, Statistical Analysis, Kriging Interpolation Method, Space-Temporal Distribution

\begin{abstract}
:
In recent years, air pollution is still a serious problem in China. Therefore, the government has further strengthened the pollution control measures for the Beijing-Tianjin-Hebei (BTH) air pollution transmission channel cities ("2+26" cities). This study used realtime PM2.5 monitoring data from 176 air quality monitoring sites in " $2+26$ " cities from 2015 to 2018 . The temporal and spatial evolution characteristics of PM2.5 concentration in " $2+26$ " cities were analysis by statistical analysis and Kriging interpolation method. The research results showed that: (1) From the analysed of time variation, the hourly variation presents a bimodal distribution, with the PM2.5 concentration reaching the peak at 9:00-10:00 O'clock and 22:00-00:00, and finally dropping to the lowest value at 16:00-17:00. The monthly change of PM2.5 concentration was almost the same, reaching the peak pollution concentration in December. The seasonal variation trend of the study area was almost the same, and the PM2.5 concentration had a small decline, except for the special changed in winter. However, autumn and winter were still the most polluted seasons, while the spring and summer were less polluted. (2) From the analysed of spatial variation, the pollution process started in November and ended slowly in March of the following year, with the worst and most extensive pollution in December. It was spread to surrounding cities by Baoding, Shijiazhuang, Xingtai and Handan in the central region, and the central area was the most polluted. In August, PM2.5 concentration was the lightest, with an average concentration of $42.4 \mu \mathrm{g} / \mathrm{m}^{3}$.
\end{abstract}

\section{INTRODUCTION}

With the rapid development of economy and industrialization, the rapid increase in the burning of fossil energy has made air pollution in China increasingly serious (Wang et al., 2014). Among them, PM2.5 (particles with particle size less than or equal to $2.5 \mu \mathrm{m}$ ) is the most polluted, and the pollution is most serious in the Pearl River Delta, Yangtze River Delta and BTH region (Cao et al., 2014, Gao et al., 2017). In 2012, China promulgated the "Environmental Air Quality Standards" (GB3095-2012). The new standard stipulates that the annual average level 1 and level 2 of the PM2.5 concentration are 15 $\mu \mathrm{g} \cdot \mathrm{m}^{3}$ and $35 \mu \mathrm{g} \cdot \mathrm{m}^{3}$ respectively. The "Work Plan for Air Pollution Prevention and Control in 2017 in BTH and Surrounding Areas" proposed the pollution control for the BTH region air pollution transmission channel cities (short for " $2+26$ " cities). It further strengthened the pollution control work in BT Hand surrounding cities. Besides, China attaches great importance to the prevention and control of air pollution. Therefore, it is of great significance to study the spatial and temporal distribution characteristics of PM2.5 concentration for the scientific treatment of air pollution.

In recent years, foreign scholars have conducted in-depth research on air pollution. For example, Li et al. (2011) discussed the application of moderate resolution imaging spectroradiometer in air quality research in parts of Asia, and analyse the AOT and PM10 concentrations in surface layer of China and Thailand from 2001 to 2019 by using simple multiple regression model. Miri et al. (2019) used the land use regression model to analyse the spatial pattern of annual and seasonal concentrations of PM1, PM2.5 and PM10 in Sabzewal. In the same year, Stafoggia et al. (2019) used the land-use random forest model to estimate the daily concentrations of PM10 and PM2.5 in Italy from 2013 to 2015, and analyse the spatial distribution of PM2.5 and PM10 annual average concentrations. In recent years, domestic scholars have done a lot of research in this research field. Spatial autocorrelation and spatial-temporal distribution characteristics of PM2.5 concentration in the Pearl River Delta region were analysed by monitoring data, and the study found that the correlation of PM2.5 concentration in the Pearl River Delta region was obvious, and the pollution in the northwest region was serious (Chang et al., 2015, Jiang et al., 2018). Wang et al. (2019) analyse the sources of PM2.5 in the autumn and winter of BTH region from 2014 to 2015 , and found that secondary particulate matter, transportation, and civil coal were the main sources. Wang et al. (2018) discussed the effects of coal-fired pollution reduction measures on the pollution control of " $2+26$ " cities, and compared the effects of various pollutants. Wang et al. (2019) took Hengshui City as an example to analyse the pollution control effect and potential source change of " $2+26$ " cities by using backward trajectory model and Concentration Weighted Trajectory (WCT). It was found that the pollution control effect was significant, but the local emissions had a greater impact than those from other sources. In the same year, Yin et al. (2019) analysed a heavy pollution process in the " $2+26$ " cities and found that adverse meteorological conditions

\footnotetext{
* Corresponding author: Juanli Jing, Email: jjlgut2008@163.com
} 
had a great impact on the concentration of pollutants. Although the intensified supervision policy of air pollution prevention and control has obvious promoting effect on improving air quality of " $2+26$ " cities, serious problems still exist in heavily polluted cities, and further deepening of comprehensive air pollution control is needed (Xiao et al., 2019). In 2017, the atmospheric pollutant removal capacity of BTH region and "2+26" cities was better, but it was constrained by meteorological conditions (Mei et al., 2019). Because the "2+26" regional emission reduction measures implemented in March 2018 were affected by meteorological conditions, regional distribution of PM2.5 concentration and local PM2.5 concentration level, the PM2.5 concentration in the region only decreased by $16.43 \%$ compared with 2013 (Chen et al., 2019).

In summary, the spatial and temporal changes of PM2.5 concentration in various regions have been analyse in detail. Many literatures indicate that the $\mathrm{BTH}$ region is the most polluted area with PM2.5 pollution in China. However, in the existing literature, BTH is the main research area, or it focuses on a certain city, or analyse a single pollution process. Although some literatures analyse the implementation effect of " $2+26$ " urban emission reduction measures, there is a lack of detailed analysis of the spatial and temporal changes of PM2.5 in the BTH atmospheric transmission channel, and the lack of hourly scale and monthly-scale concentration analysis. Therefore, this paper takes " $2+26 "$ cities as research areas to analyse the spatial and temporal distribution of PM2.5 concentration, in order to provide a basis for air pollution prevention and control work.

\section{RESEARCH AREA AND DATA SOURCES}

\subsection{Study Area}

The study area is located between $111^{\circ} 30^{\prime} \mathrm{E}-119^{\circ} 18^{\prime} \mathrm{E}$ and $34^{\circ} 11^{\prime} \mathrm{N}-41^{\circ} 3^{\prime} \mathrm{N}$ (Figure 1). The study area includes two municipalities directly under the central government of Beijing and Tianjin and some cities in Hebei, Henan, Shanxi and Shandong provinces, total 28 cities (for short " $2+26$ " cities).

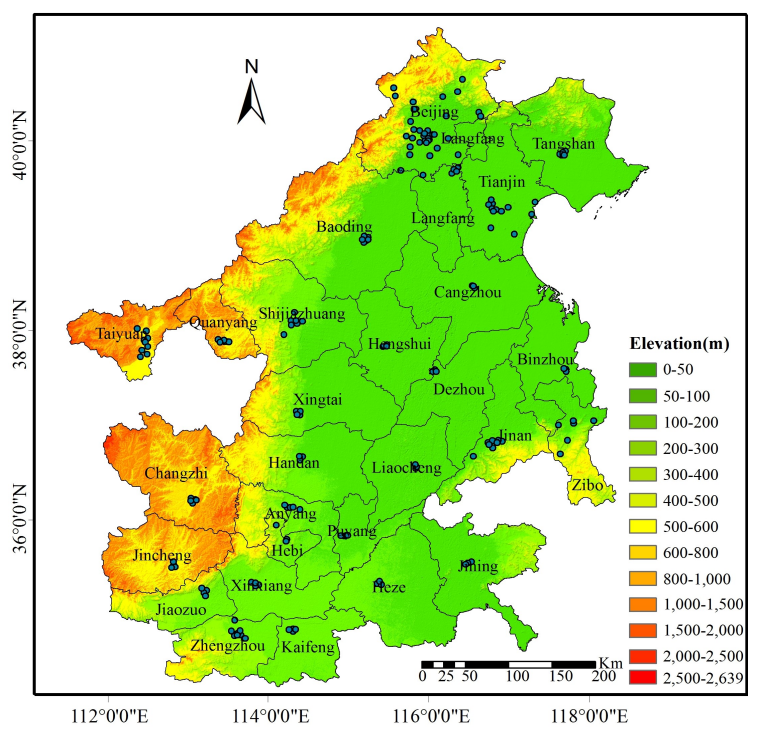

Figure 1 . The geographical location of the ' $2+26$ 'cities

The terrain of the whole region is high in the west and low in the east. Taihang Mountain is the main mountain range. The central and eastern regions are plains and basins, and the terrain is relatively flat. The climate in the region belongs to temperate monsoon climate, with distinct seasonal division. It is hot and rainy in summer and cold and dry in winter. The lack of rainfall in winter causes air pollutants to float in the air, making it become the most polluted season. The typical vegetation in the region is temperate deciduous broad-leaved forest. Because of the large population density and developed industry, it is the city cluster with the most serious PM2.5 pollution in China. It is also a transmission channel city for atmospheric pollution in the BTH region.

\subsection{Data Sources}

This study was based on the daily real-time PM2.5 monitoring data of 173 effective air quality monitoring stations in " $2+26$ " cities from 2015 to 2018 (March 1th of current year to the end of February of the next year). These include hourly data from 35 environmental monitoring sites issued by the Beijing Municipal Environmental Monitoring Center (http://www.bjmemc.com.cn/) and real-time data from 141 monitoring stations in Hebei, Henan, Shandong and Shanxi provinces issued by the China National Environmental Monitoring Centre (http://www.cnemc.cn/). Among them, 6 monitoring sites with incomplete data were eliminated. The monitoring stations are unevenly distributed in the region. There are more monitoring stations in Beijing and Tianjin than in other cities.

\section{METHOD}

MATLAB programming was used to extract the daily PM2.5 real-time concentration data of monitoring stations for 24 hours, and then calculate daily average data, composite monthly average data, and quarterly average data. Because of the random and uneven distribution of monitoring stations in the study area, therefore, this paper chose the ordinary Kriging interpolation method which has high accuracy, good mapping effect and can scientifically reflect the spatial distribution of PM2.5 concentration ( $\mathrm{Li}$ et al. 2016). The interpolation method not only considers the spatial distance relationship between the predicted point and the adjacent sample data, but also considers the positional relationship between the sample points. Because the spatial distribution structure of sample data is fully utilized, the estimation results are more realistic and the system errors are avoided more effectively. In ArcGIS software, ordinary Kriging interpolation method was used to interpolate monitoring site data. The interpolation prediction results were used to analyse the spatial distribution characteristics of PM2.5 concentration in different time scales.

\section{RESULTS AND DISCUSSION}

\subsection{Temporal Variations}

4.1.1 Daily Variation Characteristics of PM2.5 Concentration: The daily variation curve of PM2.5 concentration in " $2+26$ " cities in 2015-2018 were shown in figure 2 . It can be seen from the figure that the " $2+26 "$ cities presented a bimodal distribution phenomenon from 2015 to 2018. The reasons for the two peaks maybe due to the serious PM2.5 concentration pollution in the BTH region and surrounding cities in the past two years, which caused repeated air pollution and slowed the diffusion rate of pollutants. In 2015-2016, the two peaks appeared at 9:00-11:00 and 22:0000:00 respectively, and the hourly peak of PM2.5 concentration at night was higher than that at day. The valley value appeared between 14:00-16:00. Compared with the previous two years, 
the concentration of PM2.5 in "2+26" cities in 2017 and 2018 decreased significantly. The peak appeared at 9:00-10:00 and 22:00-00:00, and the valley value appeared at 15:00-17:00, and the valley value moved back slightly. Since 2017, the government has been implementing the "Action Plan for the Prevention and Control of Air Pollution" and "Program of Air Pollution Prevention and Control in BTH and Surrounding Areas in 2017". As a result, pollutants in various cities have been reduced, PM2.5 concentration has been greatly reduced, and the daily difference of PM2.5 mass concentration has been reduced.

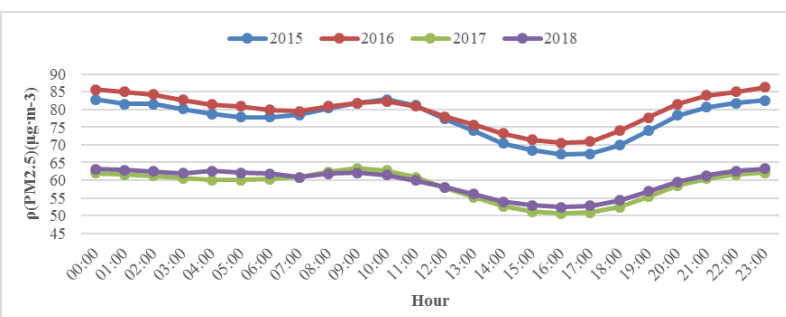

Figure 2. Hourly PM2.5 concentration in " $2+26$ " cities

4.1.2 Monthly Variation Characteristics of PM2.5 Concentration: The monthly variation characteristics of PM2.5 concentration in " $2+26$ " cities in 2015-2018 were shown in figure 3. Although the monthly variation fluctuated from 2015 to 2018 , the trend was basically the same. It began to decrease from February and fell to the minimum in August, shown a maximum in December and January. Because the " $2+26$ " cities had less rainfall in winter, cold and dry, and more stable weather, which was not conducive to the spread of pollutants. Then, December and January became the month with the highest concentration of pollutants. August was summer, with a lot of rainfall, and the rapid air circulation made the pollutants settle and spread quickly, which makes the air quality better in August. The most volatile months from 2015 to 2018 were concentrated in November to March of the following year. With exception of winter and the month in conjunction with it, all other months showed a downward trend. Compared with the year 2015, except February, there was a certain degree of decline in each month, with the largest decline in December, from $151.7 \mathrm{ug} / \mathrm{m}^{3}$ to $72.2 \mathrm{ug} / \mathrm{m}^{3}$, a decline of $52.5 \%$.February rose by $29.9 \mathrm{ug} / \mathrm{m}^{3}$, it e due to the focus of pollution control in 2017-2018 in autumn and winter. Ignore the prevention and control work at the end of winter, which led to an increase in PM2.5 concentration. Therefore, the government should strengthen pollution control work in every month and implement comprehensive pollution control.

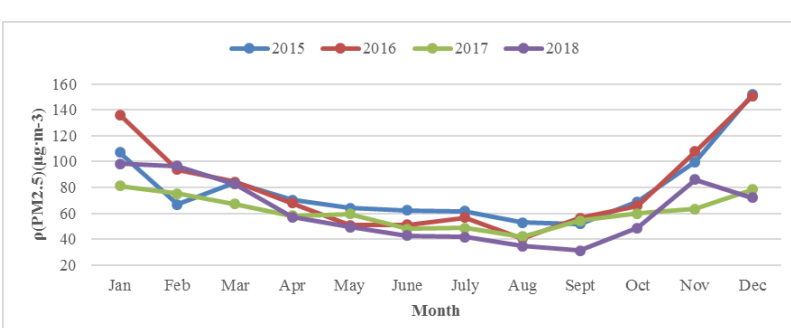

Figure 3. Monthly PM2.5 concentration in " $2+26$ " cities
4.1.3 Seasonal Variation Characteristics of PM2.5 Concentration: According to the annual cycle from March to February of the following year, the spring is from March to May, the summer is from June to August, the autumn is from September to November, and the winter is divided from December to February. The seasonal variation of PM2.5 concentration in " $2+26$ " cities were shown in figure 4 . From the year of 2015 to 2018 , the annual average concentrations of "2+26" cities were $63.8 \mathrm{ug} / \mathrm{m}^{3}, 63.6 \mathrm{ug} / \mathrm{m}^{3}, 80.4 \mathrm{ug} / \mathrm{m}^{3}$ and 81.3 $\mathrm{ug} / \mathrm{m}^{3}$ respectively, which exceeded the secondary standard (35 $\mathrm{ug} / \mathrm{m}^{3}$ ) of national average annual environmental air quality. According to seasonal analysis, the concentration of PM2.5 decreased year by year in all seasons except winter from 2015 to 2018. Winter was the most polluted season in the BTH region and the surrounding atmospheric transmission channel cities. The winter pollution was the most serious in 2016, reaching $131.7 \mu \mathrm{g} / \mathrm{m}^{3}$. The PM2.5 concentration had a significant improvement with a drop of $45.1 \mu \mathrm{g} / \mathrm{m}^{3}$ in 2017 compared with 2016. The PM2.5 concentration in the autumn and winter of 2017 has dropped significantly, and the air quality is better than the same period. Since the implementation of the "Program of Air Pollution Prevention and Control in BTH and Surrounding Areas in 2017", the PM2.5 concentration in the autumn and winter had dropped significantly in 2017 , and the air quality was better than the same period. Table 1 showed the PM2.5 concentration changes in the " $2+26$ " cities in each season. In spring and summer, the pollution degree was relatively light, the concentration difference between cities were small, the pollutant concentration in Puyang and Changzhi were the lowest, and the air quality was good. The pollution problems in autumn and winter were more serious, and the most polluted cities were Baoding and Anyang. The concentration of winter in Beijing and Tianjin were relatively low. Because Beijing is a key pollution management city, and Tianjin is a coastal city along the Bohai Bay, the air diffusion conditions are good, which causes the atmospheric pollutants to transfer and condense downwards. Therefore, the pollution in the central cities is more serious.

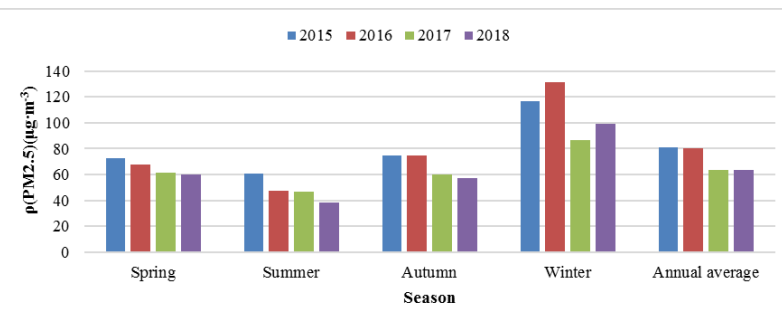

Figure 4. Seasonal PM2.5 concentration in " $2+26$ " cities

\begin{tabular}{|c|c|c|c|c|}
\hline City & Spring & Summer & Autumn & winter \\
\hline Beijing & 69.8 & 49.8 & 65.6 & 76.7 \\
Tianjin & 64.8 & 46.9 & 61.9 & 83.8 \\
Shijiazhuang & 71 & 52.8 & 80.2 & 131.4 \\
Tangshan & 72.7 & 51.5 & 69.1 & 89.6 \\
Handan & 67.5 & 57.3 & 71.9 & 133.6 \\
Baoding & 73.5 & 52.9 & 81.4 & 134.7 \\
Langfang & 60.8 & 45.4 & 64.9 & 89.6 \\
Cangzhou & 59.3 & 46.4 & 63 & 96 \\
Hengshui & 67.6 & 59.6 & 74 & 121.3 \\
Xingtai & 67.7 & 55.4 & 77.9 & 134.6 \\
\hline
\end{tabular}




\begin{tabular}{|c|c|c|c|c|}
\hline Taiyuan & 54.4 & 42.1 & 64.2 & 86.8 \\
Jinan & 65.7 & 50 & 64.5 & 101 \\
Zhengzhou & 73.3 & 46.1 & 65.5 & 121 \\
Dezhou & 67.8 & 50.3 & 70.5 & 117.9 \\
Liaocheng & 72.2 & 53.6 & 72.8 & 113.9 \\
Bingzhou & 70 & 49.2 & 65 & 94.7 \\
Zibo & 66.7 & 49.2 & 68.2 & 99.4 \\
Jining & 56.9 & 42.2 & 60.5 & 99.4 \\
Heze & 67.4 & 46.2 & 71.4 & 118.3 \\
Changzhi & 53.3 & 44.8 & 51.6 & 93 \\
Yangquan & 57.2 & 47.6 & 56.2 & 87.2 \\
Anyang & 68.6 & 48.5 & 71.8 & 140.1 \\
Kaifeng & 61.9 & 40.3 & 65.7 & 118.7 \\
Jiaozuo & 76.8 & 53.5 & 63.1 & 120.5 \\
Jincheng & 60.1 & 42.7 & 51.1 & 91.7 \\
Hebi & 55.1 & 41.3 & 60.0 & 109 \\
Xinxiang & 69.9 & 47.9 & 69.5 & 118.5 \\
Puyang & 62.2 & 40.2 & 64.6 & 120.5 \\
\hline
\end{tabular}

Table 1. Seasonal variation of PM2.5 concentration in various cities

\subsection{Spatial Variations}

4.2.1 Daily Spatial Distribution Characteristics: The Kriging interpolation method of ArcGIS software was used to interpolate the hourly data of monitoring stations in " $2+26$ " cities from 2015 to 2018. Refer to the "Environmental Air Quality Index (AQI) Technical Regulations (Trial)" (HJ6332012), the PM2.5concentration was divided into five grades: excellent, good, light pollution, medium pollution and heavy pollution. And the ArcGIS software was used to classify the ranges of 0-35-45-55-65-75-85-95-105-115-125-135-145maximum. As could be seen from figure 5, PM2.5 concentration generally presented a distribution pattern of heavy pollution in central cities and light pollution in surrounding cities. From 00:00 in Baoding city, the pollution range gradually expanded to surrounding cities, and from 9:00 to 10:00, the pollution range was the largest and the concentration value was the highest. The range of pollutants gradually decreased and the concentration gradually decreased from 12:00 to $18: 00$. By 16:00-17:00, the air quality of most cities in the region were good. The concentration of pollutants began to increase gradually after 18:00. Because 18 o 'clock was the off-duty time, the urban car flow is large, the pollutant discharge is large 。 In the evening, the air is drier and the ground is dusty. The formation of pollutants condenses in the air, causing the concentration of pollutants to rise. As the temperature of the night decreases, the humidity of the air increases, and the concentration of the pollutant decreases with the settlement of the mist at 5:00-6:00 am. However, with the evaporation of water vapor from the ground by sunlight, the pollutants were diffused into the air because of human activities. This had led to an increased in the concentration of pollutants.

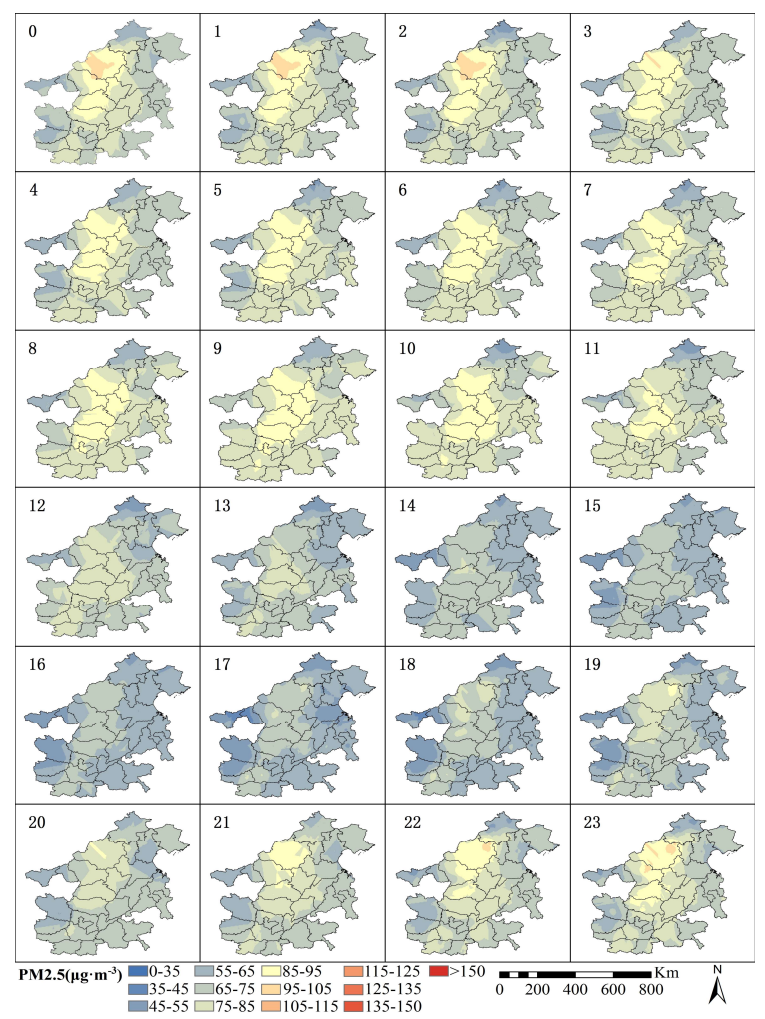

Figure 5. Spatial distribution of hourly PM2.5 concentration in the " $2+26$ " cities

4.2.2 Monthly Spatial Distribution Characteristics: It can be seen from figure 6 that the monthly concentration of PM2.5 had significant spatial variability. The spatial interpolation of the PM2.5 concentration was characterized by severe haze in the central region, relatively light haze in the surrounding area. The concentration of pollutants began to increase sharply in November each year. By December and January of the following year, the concentration of pollutants was the highest and the pollution range was the widest. Most cities began to heating in the north of China after November, which increased coal combustion. While, the air in the area was dry and less rainfall, which caused the pollutant to not descent and the concentration of pollutant increased. The central and southern cities were polluted seriously, mainly in Baoding, Shijiazhuang, Xingtai and Handan. Because of the big population density, transportation hub and developed railway transportation network in these cities, the large traffic flow and the western mountain blockade made the air mobility small, which increased accumulation of pollutant. The pollutants gradually dissipated in April every year, the PM2.5 concentration decreased, and the air quality improved. First, because the study area stopped heating, greatly reducing the emission of pollutants; Secondly, due to a lot of rainfall in the research area during spring and summer, most of the pollutants concentrated in the air settle to the ground, effectively reducing the concentration of pollutants. In summary, from November to March were still the most polluted month in the study area, the government should strengthen pollution management and reduce unnecessary pollutant emissions. 


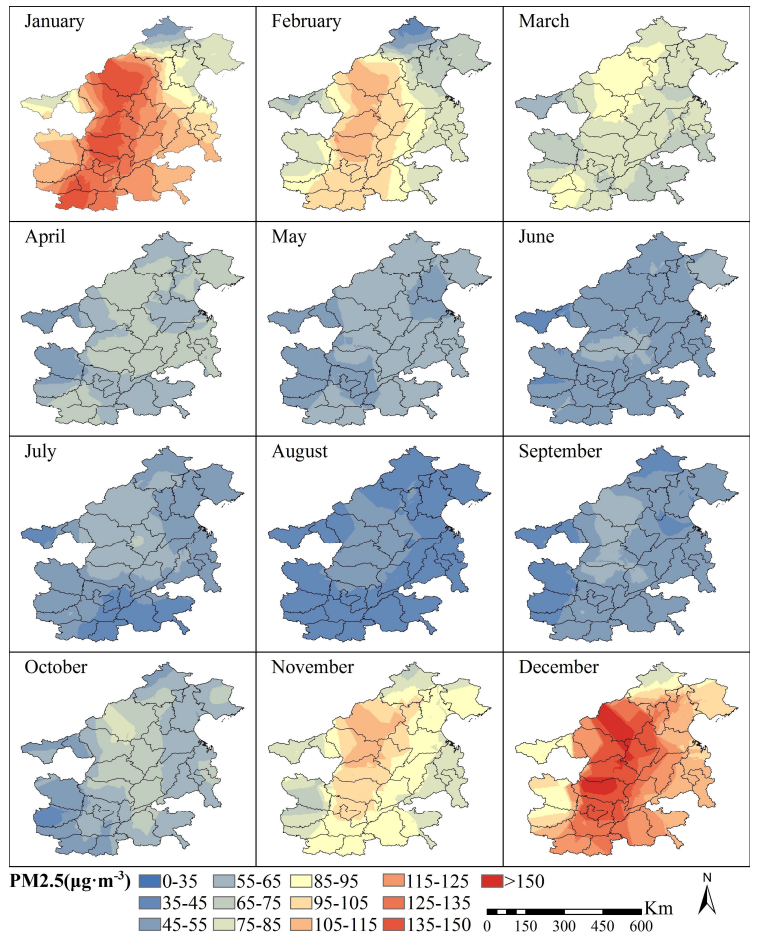

Figure 6. Spatial distribution of monthly PM2.5 concentration in the " $2+26$ " cities

4.2.3 Seasonal Spatial Distribution Characteristics: The spatial variation characteristics of PM2.5 seasonal concentration was described from figure 7.

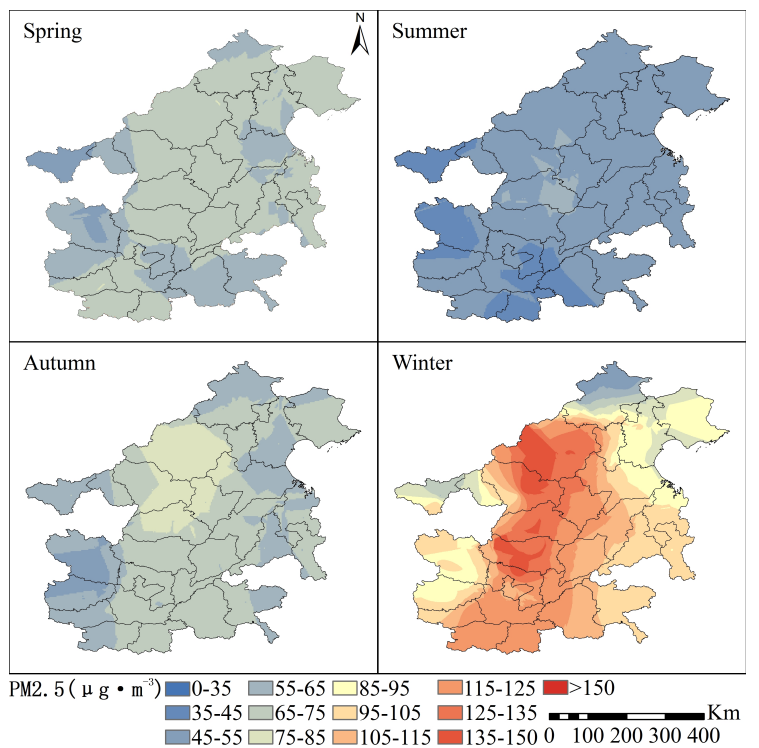

Figure 7. Spatial distribution of seasonal PM2.5 concentration in the " $2+26$ " cities

Among them, winter pollution was the most serious. Because most cities in northern China started heating in the autumn and winter seasons, a large range of coal combustion led to a rapid increase in pollutant emissions. In autumn and winter, there was less rainfall in air drying, which made the pollutants unable to settle and the concentration of pollutants increased. The air quality was good in spring and summer. The climate conditions in the study area were good in spring and summer, and the rainfall was abundant, which made the pollutants settle down and the concentration decrease. In summer, the air quality of the whole region reached a good level, with the average concentration less than $48.3 \mathrm{ug} / \mathrm{m}^{3}$. In winter, $90 \%$ of the cities in the whole region had slight pollution, and the average concentration reached $108 \mathrm{ug} / \mathrm{m}^{3}$.

\section{CONCLUSIONS}

This study was based on the real-time observation data of Beijing Municipal Environmental Monitoring Center and China National Environmental Monitoring Centre. Combined with statistical analysis and Kriging interpolation method, the variation characteristics and spatial distribution characteristics of different time scales of PM2.5 concentration in " $2+26$ " cities were analysed. The spatial and temporal distribution characteristics of PM2.5 concentration in the study area from 2015 to 2018 were discussed. The main conclusions were as follows:

1. Overall, the annual average concentration of PM2.5 in " $2+26$ " cities in 2015-2018 fluctuated between 63.6$81.3 \mu \mathrm{g} \cdot \mathrm{m}^{3}$, with an average concentration of $72.3 \mu \mathrm{g} / \mathrm{m}^{3}$, which exceeded the annual average secondary standard by twice.

2. The concentration of PM2.5 variation obviously in time scale, and the pollution of PM2.5 variation greatly in different seasons. The pollution was more serious in winter, followed by autumn, spring and summer. The change of monthly concentration was basically the same, the maximum value appeared in December and January, and the minimum value appeared in August. No matter how the season changes, the daily concentration shown a bimodal change. In a day, the maximum value was reached around 10:00 am and the minimum value was reached around 16:00 pm.

3. From 2015 to 2018, the concentration of PM2.5 in "2+26" cities was higher in central cities and lower in surrounding cities. The scope of pollution had gradually decreased, mainly in the cities of Baoding, Shijiazhuang, Xingtai and Handan, which had gradually spread to surrounding cities, and the overall appearance was "start in central region then surrounding area" pattern. The concentration of pollutants began to increase sharply in November each year. By December and January of the following year, the concentration of pollutants was the highest and the pollution range was the widest. In summer, the air quality of the whole region reached a good level and in winter, $90 \%$ of the cities in the whole region had slight pollution.

\section{ACKNOWLEDGEMENTS}

This research was financially supported by Guangxi Key Laboratory of Spatial Information and Geomatics (16-380-2508), Guangxi young and middle-aged teacher's basic ability improvement project (KY2016YB192).

\section{REFERENCES}

Cao, J. J., 2014. PM2.5 and Environment. Science Press, 8-13.

Chang, J. L., Yu, H., Luo, W. W., 2015. Spatial autocorrelation analysis of pm25 concentration in the Pearl River 
delta. Journal of Ecology and Rural Environment, 31(06), 853-858.

Chen, Z. Y., Chen, D. L., Wen, W., Zhang, Y., Kwan, M. P., Chen, B., Zhao, B., Yang, L., Gao, B. B, Li, R. Y., Xu, B.,2019. Evaluating the " $2+26 "$ regional strategy for air quality improvement during two air pollution alerts in Beijing: variations in PM2.5 concentrations, source apportionment, and the relative contribution of local emission and regional transport Atmospheric Chemistry and Physics, 19(10).

Gao, Q. X., Li, L., Ma, Z. Y., Wang, B. B., 2017. The Impacts of Synoptic Situation on Heavy Pollution Process in Autumn in Beijing during 2013-2016. Research of Environmental Sciences, 30(2), 173-183.

Jiang, C., Gong, J. Z., Sun, J. R., Chen, X. Y., 2018. Spatialtemporal evolution of pm2.5 distribution in pearl river delta region in 2013-2016. Ecology and Environmental Sciences, 27(09), 1698-1705.

Li, C., Hsu, N. C., Tsay, S. C., 2011. A study on the potential applications of satellite data in air quality monitoring and forecasting. Atmospheric Environment, 45(22), 3663-3675.

Li, J., Zhai, L., Sang, H. Y., Zhang, Y., Yuan, J., 2016.Comparison of different spatial interpolation methods for PM2.5. Science of Surveying and Mapping, 41(04), 50-54+101.

Mei, M., Zhu, R., Sun, C. Y., 2019. Study on meteorological conditions for heavy air pollution and its climatic characteristics in " $2+26$ " cities around Beijing-Tianjin-Hebei region in autumn and winter. Climate Change Research, 15(03), 270-281.

MIRI, M., GHASSOUNB, Y., DOVLATABADIA, A., Ebrahimnejad, A., Löwner, O. M., 2019. Estimate annual and seasonal PM1, PM2.5 and PM10 concentrations using land use regression model. Ecotoxicology and Environmental Safety, 174,137-145.

STAFOGGIA, M., BELLANDER T., BUCCI, S., Davoli, M., Hoogh, K. D., Donato, F. D., Gariazzo, C., Lyapustin, A.,
Michelozzi, P., Renzi, M., Scortichini, M., Shtein, A., Viegi, G., Kloog, I., Schwartz, J., 2019. Estimation of daily PM10 and PM2.5 concentrations in Italy, 2013-2015, using a spatiotemporal land-use random-forest model. Environment International.124, 170-179.

Wang, H. B., Yang, T., Wang, Z. F., He, L. T., Cui, Y. B., Geng, W., Zhu, L. M., Huang, X. F., Wang, J. R., Kong, L.,2019. Analysis of the effect of winter air pollution prevention and control in the " $2+26$ " Cities in 2017 and its potential reasonsTaking Hengshui City as an example. Acta Scientiae Circumstantiae, https://doi.org/10.13671/j.hjkxxb.2019.0217.

Wang, Y. S., Zhang, J. K., Wang, L. L., Hu, B., Tang, G. Q., Liu, Z. Y., Sun, Y., Ji, D. S., 2014. Researching significance, status and expectation of haze in Beijing-Tianjin-Hebei region. Advances in earth science, 29(3), 388-396.

Wang, T., Huang, Y., Xu, Q. C., Wang, S. Q., 2019. Source apportionment of PM2.5 in suburban area of Beijing-TianjinHebei region in autumn and winter. Environmental Science, 40(30), 1035-1042.

Wang, Y. C., Jiang, C. L., He, J. Y., Zhong, Y. Z., Song, X. H., Lei, Y., Yan, L., 2018. Air pollutant emissions reduction potential from burning coal in cities of air pollution transmission channel in Beijing-Tianjin-Hebei area. China Environmental Science, 38(07), 2401-2405.

Xiao, Q. Q., Guo, P. K., Chang, M., 2019. Characteristics and effect evaluation of air pollution prevention and control inspection results-Taking Beijing-Tianjin-Hebei and surrounding areas as an example. Journal of Arid Land Resources and Environment, 33(11), 42-48.

Yin, L. N., Chu, Y. X, Duan, J. Q., Hu, J. N., Tan., J. H., 2019. Characteristics of a Multi-Factor Superimposing Haze Episode i n '2+26' cities. Research of Environmental Sciences, https://doi org/10.13198/j.issn.1001-6929.2019.07.19. 